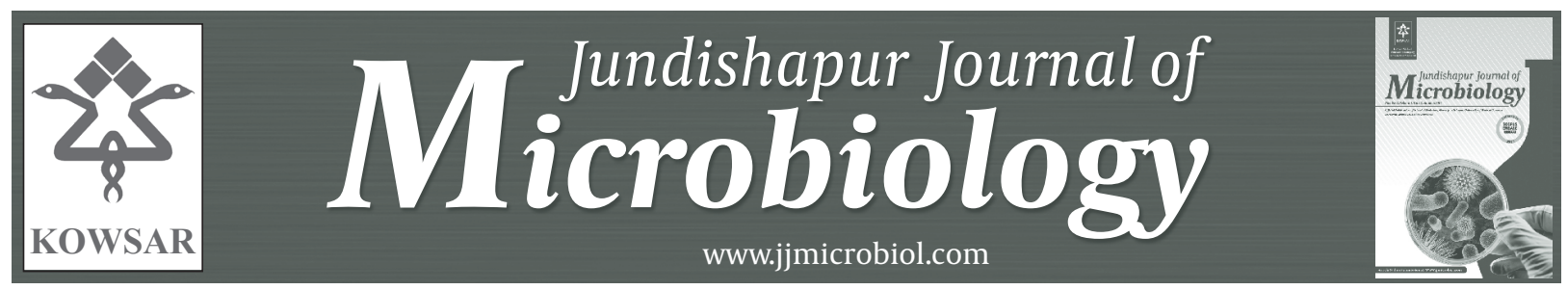

\title{
Hepatitis C Virus Subtype 6a Infection in an Iranian Patient: A Case Report
}

\author{
Faraz Salehi Moghadam ${ }^{1,2}$, Seyed Reza Mohebbi ${ }^{1,{ }^{*},}$, Seyed Masoud Hosseini ${ }^{2}$, Hanieh Mirtalebi ${ }^{1}$, \\ Sara Romani ${ }^{1}$, Pedram Azimzadeh ${ }^{1}$, Azar Sanati ${ }^{1}$, Mohammad Reza Zali ${ }^{1}$ \\ ${ }^{1}$ Gastroenterology and Liver Diseases Research Center, Shahid Beheshti University of Medical Sciences, Tehran, IR Iran \\ ${ }^{2}$ Department of Microbiology, Faculty of Biological Sciences, Shahid Beheshti University of Medical Sciences, Tehran, IR Iran \\ ${ }^{*}$ Corresponding author: Seyed Reza Mohebbi, 7th Floor of Taleghani Hospital, Velenjak, Tehran, IR Iran. Tel.: +98-2122432514, Fax: +98-2122432515, E-mail: \\ srmohebbi@gmail.com.
}

\section{A B S T R A C T}

Hepatitis C virus (HCV) isolates have been divided into six major genotypes, each of them further divided into several subtypes. Previous studies have shown that the most frequent genotype in Iranian patients with HCV infection is 1a, followed by $3 a, 1 \mathrm{~b}$ and 4 . Infections with genotype 6 isolates have not previously been observed in these patients. In this report, we will describe the first diagnosis of HCV genotype-6 infection in Iran.

The case was a 62-year-old man with positive anti-HCV antibody. Alanine aminotransferase and aspartate aminotransferase levels were 14 and $32 \mathrm{IU} / \mathrm{L}$ respectively. Viral RNA was extracted from plasma. HCV RNA level was determined using real-time reverse transcription polymerase chain reaction (PCR). Following the synthesis of the complementary DNA, 5'-UTR/core region of the HCV genome was amplified and subjected to direct sequencing. Genetic distances were estimated and phylogenetic tree was constructed. HCV viral load was 9,572,718 IU/mL. The mean inter-genotypic distance between the case sequence and the corresponding sequences of other genotype 6 isolates was 3.7\%. In the phylogenetic tree, the 5'-UTR/core sequence of the subject was located in a cluster representing HCV subtype 6a.

The patient was infected with HCV subtype 6a. Prior to this case, there have been no previous reports on the isolation of this genotype/subtype from any other Iranian patient. Previous epidemiological studies provide valuable information about the distribution patterns of different HCV genotypes. However, infection with genotypes other than common ones should be flagged by specialists and diagnostic laboratories, especially in patients with high-risk behavioral backgrounds.

Keywords: Hepatitis C Virus; Genotype 6; Iran

Copyright (c) 2013, Ahvaz Jundishapur University of Medical Sciences; Published by Kowsar Corp.

Article type: Case Report; Received: 28 May 2012; Revised: 17 Jul 2012; Accepted: 08 Aug 2012; Epub: 01 Jun 2013; Ppub: Jun 2013

Implication for health policy/practice/research/medical education:

This article reports the first ever case of hepatitis C virus genotype-6 infection in Iran.

-Please cite this paper as:

Salehi Moghadam F, Mohebbi SR, Hosseini SM, Mirtalebi H, Romani S, Azimzadeh P, et al. Hepatitis C Virus Subtype 6a Infection in an Iranian Patient: A Case Report. Jundishapur J Microbiol. 2013;6(4):e6560. DOI: 10.5812/jjm.6560.

Copyright (C) 2013, Ahvaz Jundishapur University of Medical Sciences; Published by Kowsar Corp.

This is an Open Access article distributed under the terms of the Creative Commons Attribution License (http://creativecommons.org/licenses/by/3.0), which permits unrestricted use, distribution, and reproduction in any medium, provided the original work is properly cited. 


\section{Background}

Hepatitis C virus (HCV) is a blood-borne pathogen that has infected about 170 million people worldwide (1). There are several modes of HCV transmission including blood transfusion, intravenous drug abuse, tattooing, transplantation from an infected donor, high-risk sexual exposure and birth to an infected mother. Using surgical and dental equipment which are not appropriately disinfected and sterilized can be additional sources of HCV transmission (2).

Six major HCV genotypes and more than 90 subtypes have been indentified thus far (3). HCV genotype has clinical importance as it determines the treatment duration with the current standard anti-HCV agents, pegylated interferon- $\alpha$ and ribavirin. Infections with genotype 1 are more challenging to treat with this medication regimen $(4,5)$. Distribution of HCV genotypes has also epidemiological significance. Genotypes 1, 2 and 3 are responsible for HCV infections in more than $90 \%$ of cases in North and South America, Europe and Japan (6). Genotypes 4 and 5a are frequent genotypes in Central Africa and South Africa respectively, whereas genotypes 1 and 2 are responsible for most of the HCV infections in West Africa. In Asia, the most frequent genotypes are 3 and 6 (7). HCV genotype 6 is generally restricted to Southeast Asia (8). In the Middle East, whereas, $4 \mathrm{a}$ is the predominant genotype in Arab countries, $1 \mathrm{~b}$ and 3 are the most frequent genotypes in Turkey and Pakistan respectively $(9,10)$. The predominant genotype in Iran is 1a followed by $3 a$ and $1 b(11,12,13,14)$. This paper reports the first ever case of HCV subtype-6a infection in Iran as no genotype- 6 infection has been reported previously.

\section{Case Presentation}

A 62-year-old man with positive anti-HCV antibody was referred to Taleghani Hospital (Tehran, Iran). The patient has had no history of intravenous drug abuse, high-risk sexual activity nor has he shared shaving razors. The patient had a history of periodontal procedures, lower and upper gastrointestinal endoscopy. He underwent spine surgery in Hong Kong in 1977. The patient has had a Helicobacter pylori infection for 2 years. He has also been suffering from Parkinson's disease for the last ten years. He has made trips to Britain (in 1991) and the United States (in 2010). He has had a history of admission to the hospital for respiratory difficulties. Serological tests for hepatitis B surface antigen (HBs-Ag) and antibodies to hepatitis A (IgM), hepatitis B core antigen (anti-HBc Ab) and hepatitis $C$ virus (anti-HCV Ab) were performed using enzyme-linked immunosorbent assay (DIAPRO, Milan, Italy). Laboratory test results are shown in Table 1 . Viral RNA was extracted from patient's plasma using QIAamp Viral RNA mini kit (QIAGEN, Hilden, Germany).

Table 1. Laboratory Test Results of the Patient.

\begin{tabular}{|c|c|c|c|c|}
\hline \multicolumn{2}{|c|}{ Laboratory Test } & Result & Laboratory Test & Result \\
\hline \multicolumn{2}{|c|}{ W.B.C, 1000/Cumm } & 4.33 & $\operatorname{ALT}^{\mathrm{a}}(\mathrm{IU} / \mathrm{L})$ & 14 \\
\hline \multicolumn{2}{|c|}{ R.B.C, 1000/Cumm } & 4.3 & $\operatorname{AST}^{\mathrm{a}}(\mathrm{IU} / \mathrm{L})$ & 32 \\
\hline $\begin{array}{l}\text { Platelet, } \\
\text { /Cumm }\end{array}$ & 1000 & 160 & $\mathrm{HBs}^{\mathrm{a}}$ Antigen & $\mathrm{N}$ \\
\hline $\begin{array}{l}\text { Total } \\
\text { mg/dL }\end{array}$ & Bilirubin, & 0.8 & Anti-HBc & $\mathrm{N}$ \\
\hline $\begin{array}{l}\text { Direct } \\
\mathrm{mg} / \mathrm{dL}\end{array}$ & Bilirubin, & 0.2 & Anti-HCV & $\mathrm{p}^{\mathrm{a}}$ \\
\hline $\mathbf{A L P}^{\mathrm{a}}, \mathbf{I U} / \mathbf{I}$ & & 219 & Anti-HAV IgM & $\mathrm{N}^{\mathrm{a}}$ \\
\hline
\end{tabular}

a Abbreviations: ALT, Alanine aminotransferase; AST, aspartate aminotransferase; ALP, Alkaline phosphatase; N, Negative; P, Positive.

HCV viral load was determined using HCV Real Time RT-PCR kit (Liferiver, Shanghai, China). Complementary DNA was synthesized using random hexamer primers and RevertAid Reverse Transcriptase (Fermentas, Vilnius, Lithuania) according to the manufacturer's protocol. The 5'-UTR/Core region was amplified using PCR with primers NCRF: 5'- GGAACTACTGTCTTCACGCAGAAAGC -3' and NCRR: 5'- GAAGCCGCACGTAAGGGTATCG -3'. Reaction conditions were $5 \mathrm{~min}$ at $95^{\circ} \mathrm{C}$, followed by 35 cycles of $60 \mathrm{~s}$ at $94^{\circ} \mathrm{C}, 40 \mathrm{~s}$ at $63{ }^{\circ} \mathrm{C}$ and $60 \mathrm{~s}$ at $72^{\circ} \mathrm{C}$, with a final extension step for 7 minutes at $72^{\circ} \mathrm{C}$. PCR product was direct sequenced using amplification primers. Phylogenetic tree was constructed using Molecular Evolutionary Genetic Analysis (MEGA) version 4.

HCV RNA level was 9,572,718 IU/mlL. The 5'-UTR/core sequence of the HCV isolate was compared with the corresponding region of the reference sequences retrieved from GenBank database. Genetic distances were calculated using Kimura two-parameter algorithm (15). The mean inter-genotypic distance between the 5'-UTR/core sequence of the HCV isolate obtained from the patient (GenBank accession number JQ341409) and corresponding regions of other genotype 6 isolates was 3.7\%. The mean percentage of the inter-genotypic distance of the mentioned sequence from other genotypes was estimated to be 12.4-15.7 (Table 2). Phylogenetic tree was constructed and assessed by a bootstrap resampling test with 1000 replicates using MEGA version 4 (Figure 1). In the phylogenetic tree, the subject nucleotide sequence is classified as HCV subtype $6 a$. 
Table 2. Mean Percentage Nucleotide Distance Between the Iranian Isolate and Different HCV Genotypes (Inter-Genotypic Sequence Diversity) Based on the 5'-UTR/Core Region.

\begin{tabular}{|c|c|c|c|c|c|c|}
\hline Genotype & $\mathbf{I R}^{\mathrm{a}}$ & 1 & 2 & 3 & 4 & 5 \\
\hline 1 & 12.48 & & & & & \\
\hline 2 & 15.32 & 15.15 & & & & \\
\hline 3 & 15.62 & 14.15 & 18.64 & & & \\
\hline 4 & 13.90 & 10.61 & 14.76 & 15.70 & & \\
\hline 5 & 15.70 & 10.79 & 15.46 & 13.70 & 12.09 & \\
\hline 6 & 3.70 & 12.59 & 15.55 & 15.61 & 14.70 & 14.96 \\
\hline
\end{tabular}

${ }^{\mathrm{a}}$ Iranian isolate

Figure. Phylogenetic Tree Constructed Based on the 5'-UTR/Core Region of HCVUsing Neighbor Joining Method.

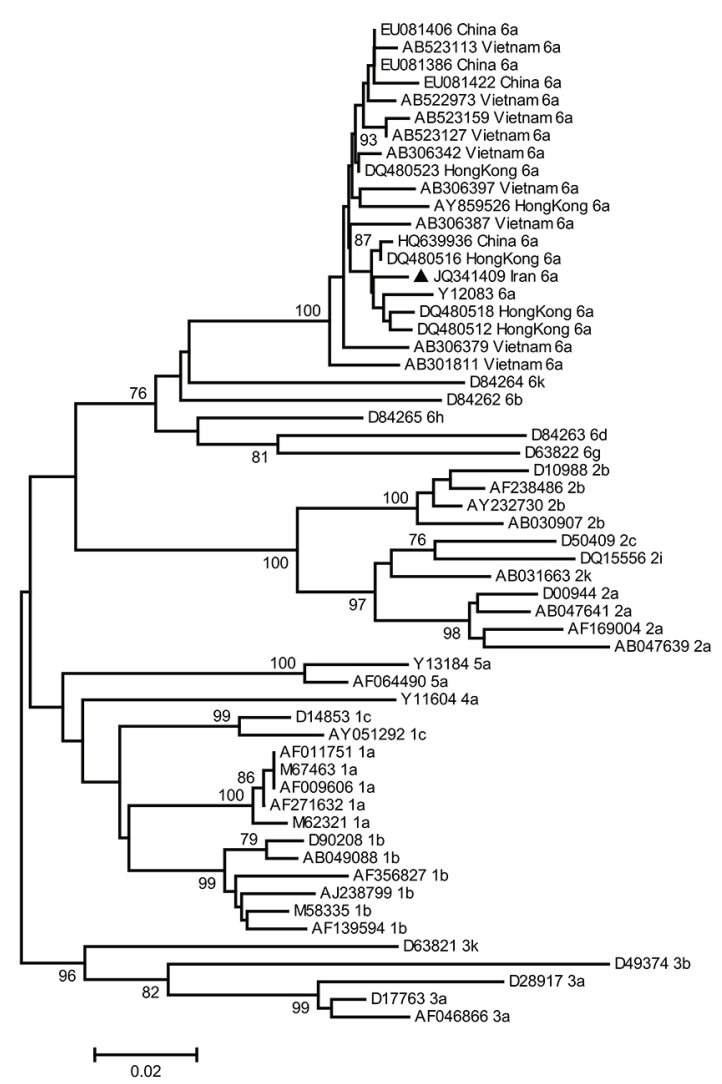

The Iranian HCV subtype 6a isolate (indicated by a black triangle) was compared to HCV reference sequences and additional subtype 6a isolates from Hong Kong, Vietnam and China retrieved from GenBank. The percentages of bootstrap values (1000 replicates) are shown by numbers at the nodes.

\section{Discussion}

Distribution of HCV genotype 6 is mainly restricted to Southeast Asia and it is a rare or low-prevalence type in other parts of the world (16). Studies indicate that HCV genotype 6 is responsible for 50\% of HCV infections in Myanmar and Vietnam $(17,18)$. Moreover, genotype 6 is the second most common HCV genotype among blood donors in Hong Kong (19). It should be mentioned that in the United States, one-third of HCV-positive immigrants from Southeast Asia are infected with various subtypes of genotype 6. Furthermore, HCV-6 has been observed in Cambodian and Vietnamese immigrants in Canada (16).

Previous studies have shown that the predominant HCV subtype in Iran is 1a followed by 3a. Other genotypes that have been identified in Iran are 1b, 2 and 4 (11-14). Samimirad et al. in 2004 studied 125 Iranian patients. They reported the existence of genotypes $1 \mathrm{a}, 3 \mathrm{a}, 1 \mathrm{~b}$ and 4 in the studied population (11). Kabir et al. in 2006 reported subtypes $1 \mathrm{a}, 3 \mathrm{a}$ and $1 \mathrm{~b}$ from 156 studied patients (12). In a different study in 2007, 2231 hepatitis C patients were tested by Keyvani et al. and subtypes 1a, 3a and $1 \mathrm{~b}$ were detected (13). In 2010, Ziyaeyan et al. isolated HCV genotypes 3a, 1a, $1 \mathrm{~b}$ and 2 from 634 studied individuals (14).

In this paper, we are reporting the first HCV genotype- 6 infection diagnosed in an Iranian patient. The patient has had a history of multiple risk factors including a spine surgery in Hong Kong in 1977. Genotype 6 is currently the second most common genotype in Hong Kong. Due to the fact that HCV was identified in 1989 and the blood-screening programs started in the 1990's, there is limited data on HCV epidemiology and geographical distribution of its genotypes prior to this time. Tanaka et al. in 2006, used the coalescent theory to investigate the past population dynamic of some HCV subtypes sampled from various countries including subtype 6a from Hong Kong. They showed that the exponential growth of HCV6 a population in Hong Kong occurred in the late 1970's (20). Although the patient travelled to the United States in 2010, he has not articulated any high-risk exposure to any infectious sources of HCV during his trip. The data suggests that the spine surgery in Hong Kong in 1977 may have been the source of the HCV transmission in this particular case.

The current standard therapy for hepatitis C infection is pegylated interferon alpha in combination with ribavirin. The treatment duration and outcome typically 
depends on the HCV genotype. Whereas HCV genotypes 2 and 3 are responsive to the therapy in $70-80 \%$ of cases, genotypes 1 and 4 are considered to be difficult to eradicate with sustained virological response (SVR) rates around $50 \%(4,5,21)$. The SVR rate for genotype- 6 infection is higher than that seen in genotype 1 infection but lower than that of genotypes 2 and 3 (22-24). Due to these facts, determining HCV genotype prior to considering a specific therapy protocol is of utmost importance. Iran is a low prevalence country in terms of HCV infection.

Due to increasing globalization, it is possible to encounter HCV genotypes or subtypes not previously reported in a specific geographical region. In this regard, diagnostic centers must consider the possibility of infections with genotypes that are rare or not previously reported in their region. Epidemiological studies are important to investigate different HCV genotypes distribution in various countries. However, completely relying on epidemiological data may prevent clinical diagnostic laboratories from considering $\mathrm{HCV}$ genotypes other than the common categories. In some cases, the patient may have been infected by a HCV genotype that was not observed in a region/country. If a commercial diagnostic kit or an in-house technique for HCV detection cannot detect such genotypes, it would produce a false negative result. The patient would thereby be a HCV carrier without a proper diagnosis and consequently can cause the spread of HCV in their family and eventually in their community. This being a case in point for the discussed issue highlights the fact that Iranian laboratories and physicians must not rule out the possibility of the HCV genotype- 6 infection. While in more than $90 \%$ of hepatitis $\mathrm{C}$ cases in Iran, subtypes 1a, 3a or $1 \mathrm{~b}$ are responsible for the infection, laboratories must consider HCV diagnostic techniques and materials (i.e. primers and molecular probes) by which all HCV genotypes can be detected.

In view of this report, further screening of groups with high-risk behavioral backgrounds, especially people who have travelled to foreign countries (particularly endemic regions) is needed. It is advised there be more a precise determination of the prevalence of various HCV genotypes/subtypes in Iranian population.

\section{Acknowledgements}

None declared.

\section{Financial Disclosure}

None declared.

\section{Funding/Support}

None declared.

\section{Authors' Contribution}

None declared.

\section{References}

1. WHO . Hepatitis C-global prevalence (update). Wkly Epidemiol Rec. 1999;49:425-427.

2. Alter MJ. Epidemiology of hepatitis C virus infection. World J Gastroenterol. 2007;13(17):2436-2441.

3. Simmonds P, Holmes EC, Cha TA, Chan SW, McOmish F, Irvine B, et al. Classification of hepatitis $C$ virus into six major genotypes and a series of subtypes by phylogenetic analysis of the NS-5 region. J Gen Virol. 1993;74(Pt 11):2391-2399.

4. Manns Michael P, McHutchison John G, Gordon Stuart C, Rustgi Vinod K, Shiffman Mitchell, Reindollar Robert, et al. Peginterferon alfa-2b plus ribavirin compared with interferon alfa- $2 \mathrm{~b}$ plus ribavirin for initial treatment of chronic hepatitis C: a randomised trial. Lancet. 2001;358(9286):958-965.

5. Fried MW, Shiffman ML, Reddy KR, Smith C, Marinos G, Gonçales Jr FL, et al. Peginterferon alfa-2a plus ribavirin for chronic hepatitis C virus infection. N Engl J Med. 2002;347(13):975-982.

6. Smith DB, Pathirana S, Davidson F, Lawlor E, Power J, Yap PL, et al. The origin of hepatitis C virus genotypes. J Gen Virol. 1997;78(2):321-328.

7. Simmonds P. Genetic diversity and evolution of hepatitis $\mathrm{C}$ virus-15 years on. J Gen Virol. 2004;85(11):3173.

8. Lu L, Li C, Fu Y, Gao F, Pybus OG, Abe K, et al. Complete genomes of hepatitis $C$ virus (HCV) subtypes $6 c, 61,60,6 p$ and $6 q$ : completion of a full panel of genomes for HCV genotype 6. J Gen Virol. 2007;88(5):1519-1525.

9. Ramia S, Eid-Fares J. Distribution of hepatitis $C$ virus genotypes in the Middle East. Int J Infect Dis. 2006;10(4):272-277.

10. Idrees Muhammad, Riazuddin Sheikh. Frequency distribution of hepatitis $C$ virus genotypes in different geographical regions of Pakistan and their possible routes of transmission. BMC Infect Dis. 2008;8(1):69.

11. Samimi-Rad Katayoun, Nategh Rakhshandeh, Malekzadeh Reza Norder Helene, Magnius Lars. Molecular epidemiology of hepatitis $C$ virus in Iran as reflected by phylogenetic analysis of the NS5B region.J Med Virol. 2004;74(2):246-252

12. Kabir Ali, Alavian Seyed-Moayed, Keyvani Hussein. Distribution of hepatitis $\mathrm{C}$ virus genotypes in patients infected by different sources and its correlation with clinical and virological parameters: a preliminary study. Comp Hepatol. 2006;5(1):4.

13. Keyvani H, Alizadeh AHM, Alavian SM, Ranjbar M, Hatami S. Distribution frequency of hepatitis C virus genotypes in 2231 patients in Iran. Hepatol Res. 2007;37(2):101-103.

14. Ziyaeyan M, Alborzi A, Jamalidoust M, Badiee P, Moeini M, Kadivar A. Prevalence of hepatitis $C$ virus genotypes in chronic infected patients, southern Iran. Jundishapur J Microbiol. 2011;4(3):141-146.

15. Kimura M. A simple method for estimating evolutionary rates of base substitutions through comparative studies of nucleotide sequences.J Mol Evol.1980;16(2):111-120.

16. Chao DT, Abe K, Nguyen MH. Systematic review: epidemiology of hepatitis $C$ genotype 6 and its management. Aliment Pharmacol Ther. 2011;34:286-296.

17. Lwin AA, Shinji T, Khin M, Win N, Obika M, Okada S, et al. Hepatitis $C$ virus genotype distribution in Myanmar: predominance of genotype 6 and existence of new genotype 6 subtype. Hepatol Res. 2007;37(5):337-345.

18. Noppornpanth S, Lien TX, Poovorawan Y, Smits SL, Osterhaus ADME, Haagmans BL. Identification of a naturally occurring recombinant genotype $2 / 6$ hepatitis $\mathrm{C}$ virus. J Virol. 2006;80(15):7569-7577.

19. Prescott LE, Simmonds P, Lai CL, Chan NK, Pike I, Yap PL, et al. Detection and clinical features of hepatitis $C$ virus type 6 infections in blood donors from Hong Kong. J Med Virol. 1996;50(2):168-175.

20. Tanaka Y, Kurbanov F, Mano S, Orito E, Vargas V, Esteban JI, et al. Molecular tracing of the global hepatitis $C$ virus epidemic predicts regional patterns of hepatocellular carcinoma mortality. Gastroenterology. 2006;130(3):703-714.

21. Kamal SM, Nasser IA. Hepatitis C genotype 4: what we know and what we don't yet know. Hepatology. 2008;47(4):1371-1383.

22. Dev AT, McCaw R, Sundararajan V, Bowden S, Sievert W. Southeast Asian patients with chronic hepatitis C: the impact of novel genotypes and race on treatment outcome. Hepatology. 
2002;36(5):1259-1265.

23. Hui CK, Yuen MF, Sablon E, Chan AOO, Wong BCY, Lai CL. Interferon and ribavirin therapy for chronic hepatitis $C$ virus genotype 6: a comparison with genotype 1.J Infect Dis. 2003;187(7):1071-1074.
24. Yuen MF, Lai CL. Response to combined interferon and ribavirin is better in patients infected with hepatitis $C$ virus genotype 6 than genotype 1 in Hong Kong. Intervirology. 2006;49(1-2):96-98. 